\title{
The Influence of the Tannic Acid on the Expression of the Connexins 45 in a Rat Kidney Damaged by the Chronic Hyperglycemia
}

\author{
Mia Šarić ${ }^{1}$, Tomislav Mašek ${ }^{2}$, Natalija Filipović ${ }^{1 *}$ \\ ${ }^{I}$ Department of Anatomy, Histology and Embriology, Laboratory for Neurocardiology, University of Split \\ School of Medicine, Šoltanska 2, 21000 Split, Croatia \\ ${ }^{2}$ Department of Animal Nutrition and Dietetics, University of Zagreb Faculty of Veterinary Medicine, Zagreb, \\ Croatia
}

*Corresponding Author: Natalija Filipović, Department of Anatomy, Histology and Embriology, Laboratory for Neurocardiology, University of Split School of Medicine, Šoltanska 2, 21000 Split, Croatia, Email: natalija.filipovic@mefst.hr

\begin{abstract}
The aim was to demonstrate the potential negative effect of the tannic acid on the expression of connexin 45 in rat kidney damaged by the chronic hyperglycemia, due to a need for critical assessment of the positive effects of the use of tannic acid in the treatment of many diseases. Twelve male Wistar rats were used in the trial over a period of twenty weeks. The rats were divided into three groups of four rats. The first group of rats was receiving a drinking water (control group, C). The second group was receiving $30 \% \mathrm{w} / \mathrm{v}$ sucrose solution in drinking water (sucrose group, Suc), while the third group received $30 \% \mathrm{w} / \mathrm{v}$ sucrose solution and $0.1 \% \mathrm{w} / \mathrm{v}$ tannic acid in drinking water for 20 weeks (sucrose +tannic acid group, Suc+TA). Pathohistologically, we observed damage of the kidneys caused by the hyperglycemia, while damage was more expressed in the Suc/TA group. Analysis of the microphotographs showed that high sucrose treatment caused reduced expression of connexin 45 in the proximal tubules of the kidney, and the addition of the tannic acid made the reduction statistically significant $(p<0.05)$. Based on the results, we concluded that the tannic acid in combination with the chronic hyperglycemia, in the dosage of $0.1 \%$ in drinking water decreases the expression of the connexin 45 in the proximal tubules of the rat kidney.
\end{abstract}

Keywords: diabetes mellitus type 2, tannic acid, connexins, chronic sucrose treatment

\section{INTRODUCTION}

Diabetic nephropathy (DN) is one of the most serious complications of diabetes mellitus (DM), causing almost half of all cases of endstage renal disease in the United States (de Boer et al., 2011). Kidneys are important for homeostasis of glucose, cause their role in gluoconeogenesis, filtration, re-absorption and secretion of the glucose. Hence, the changes in the kidney function are involved in development of hyperglycaemia and type 2 diabetes (DM2). Direct connection between hyperglycemia and damage of the renal cells has been established in many studies (Rai et al., 2015) (Michishita et al., 2017). Increase in glucose re-absorption as a consequence of the increased blood glucose and renal re-absorption is one of the mechanisms in development of the hyperglycaemia and consequent microvascular complications (Triplitt, 2012). Hyperglycaemia causes renal damage directly and indirectly, by haemodynamic modifications. It is responsible for glomerular hyperfiltration and microalbuminuria, which in turn increase the expression of the pro-fibrotic transforming growth factor-beta (TGF $\beta$ ) (Schena and Gesualdo, 2005, Kanwar et al., 2008). Hyperglycaemia and the hyperfiltration cause the damage of the glomeruli and consequent proteinuria (Triplitt, 2012) (Sampanis, 2008).

Connexins are trans-membrane proteins that form gap junctions and hemi-channels called connexons. Gap junctions enable direct exchange of the ions and small molecules between cells, while the connexons are important for exchange between the cell and the extracellular space (Sampanis, 2008, Lawrence et al., 1978, Saez et al., 1989). Between twenty known isoforms of the connexins, nine was found in kidney: Cx26, Cx30.3, Cx31, Cx32, Cx37, Cx40, Cx43, Cx45 and Cx46 and their roles are still not fully investigated (Hanner et 
The Influence of the Tannic Acid on the Expression of the Connexins 45 in a Rat Kidney Damaged by the Chronic Hyperglycemia

al., 2010). Isoforms $\mathrm{Cx} 37, \mathrm{Cx} 40$ and $\mathrm{Cx} 43$ are expressed in renal vasculature, predominantly between endothelial cells of the afferent arteriolae (Arensbak et al., 2001). Cx45 was found in smooth muscle cells of the renal arterioles and mesangial cells, where it regulates constriction and dilation, taking a part in rennin secretion and control of the blood pressure (Hanner et al., 2010). It was also found in podocytes and proximal tubular cells (PTCs) (Hanner et al., 2010). Its expression in distal tubular cells has been controversial (Butterweck et al., 1994, Silverstein et al., 2003).

It was observed that DM changes the expression and regulation of the connexins, which are important in development and function of many organs (Hanner et al., 2010). Chronic hyperglycaemia changes the number of gap junctions, damaging consequently the blood vessels and nerves, causing the atherosclerosis and slowing the wound healing (Zhou et al., 2015, Hamelin et al., 2009).

Tannic acid (TA) is a hydrophylic polyphenolic compound present in broad spectrum of vegetable foods e.g. red vine, cereals, fruits, legumes, green tea and medicinal herbs (Chu et al., 2016). TA strongly protects cells from the oxidative stress, by inhibition of the lipid peroxidation and development of reactive oxygen species (Tikoo et al., 2008, Chung et al., 1998, Zhao et al., 2014, Akiyama et al., 2001, Yokozawa et al., 1993). Recently, anti-diabetic effects have been attributed to the TA. It was observed that TA decreases the post-prandial rise in blood glucose (Gin et al., 1999), stimulates glucose transport in the cells and inhibits differentiation of the adipocytes (Tikoo et al., 2008). In contrast, certain studies accentuated prooxidative and cytotoxic effects of the TA (Cao et al., 1997, Teixeira et al., 2005, Labieniec and Gabryelak, 2003, Gupta et al., 2002). Anti- or pro-oxidative effects of the TA depend on different factors, including the used dosage and the particular tissue and organ (Masek and Starcevic, 2016, Chung et al., 1998).

Taking into consideration these investigations, we aimed to explore potentially negative effects of the tannic acid treatment on expression of connexins in kidney of rats damaged by chronic sucrose treatment, in order to critically consider benefits and usage of the tannic acid in treatment and prevention of different diseases, especially in diabetic patients.

\section{MATERIAL AND METHODS}

\subsection{Experimental Animals}

Study was made on twelve male Wistar rats. Experimental protocols were approved by the National Ethics Committee (EP 13/2015) and Veterinary Directorate, Ministry of Agriculture, Republic of Croatia. Animals were held in controlled environmental conditions (temperature $22 \pm 1^{\circ} \mathrm{C} ; 12$-hr light/dark cycle). Three groups were formed, on a base the drinking solutions. The first group of rats was receiving a drinking water (control group, C). The second group was receiving $30 \% \mathrm{w} / \mathrm{v}$ sucrose solution in drinking water (sucrose group, Suc), while the third group received $30 \%$ w/v sucrose solution and $0.1 \% \mathrm{w} / \mathrm{v}$ tannic acid in drinking water (sucrose +tannic acid group, Suc+TA). All rats were fed ad libitum with rodent feed (containing 18\% protein and 5\% fat). A glucometer was used for measuring of blood glucose. The rats were euthanized under the general anaesthesia (Narketan®, $80 \mathrm{mg} \mathrm{kg}-$ 1 b.m. + Xylapan®, 12 mg kg-1 b.m., i.p., Vétoquinol, Bern, Switzerland) 20 weeks after the beginning of the experiment.

\subsection{Tissue Collection and Processing}

Kidneys were harvested and immersed in Zamboni's fixative (4\% paraformaldehyde and $0.20 \%$ picric acid in $0.1 \mathrm{M}$ phosphate-buffered saline (PBS), $\mathrm{pH}$ 7.4). Tissue was washed in PBS and dehydrated in raising concentrations of ethanol, cleared in xylene and embedded in paraffin-wax, by using a standard procedure (Filipovic et al., 2014). Paraffin blocks were cut in $5 \mu \mathrm{m}$ thick sections, which were mounted on histological glass slides. After deparaffinization, sections were stained by using standard histological trichrome staining or immunohistochemistry.

\subsection{Trichrome-Mallory Staining}

The trichrome-Mallory staining was performed as described previously (Agnic et al., 2014). Sections were immersed in hematoxylin and incubated (for 5 minutes). Differentiation in tap water followed. Then they were immersed in acid fuchsin and incubated (for 1 minute). They were rinsed few times with distilled water, and then incubated in $1 \%$ phosphomolybdic acid (for 1 minute). After the brief rinsing in distilled water, they were immersed in aniline blue and incubated for 15 minutes. Then they were rinsed in distilled water and incubated in $1 \%$ acetic acid (1-5 minutes), which was followed 
with dehydration in ethanol and xylene and coverslipping.

\subsection{Immunohistochemistry}

After deparaffinization, slides were heated in citrate buffer in purpose of antigen retrival. After cooling at room temperature and washing in PBS, slides were incubated overnight in primary rabbit policlonal Anti-Connexin 45 / GJA7 antibody - C-terminal (ab135474; Abcam, Cambridge, UK), diluted at 1:100. Next day, sections were washed in PBS and incubated for 90 minutes in secondary Rhodamine Red TMconjugated donkey anti rabbit antibody (711295-152; Jackson ImmunoResearch Laboratories, Inc., Baltimore, PA, SAD), diluted at 1:300. Slides were then washed in PBS, dried in air and coverslipped (Immu-Mount, Shandon, Pittsburgh, PA, SAD). Control staining was made by omission of the primary antibody from the described procedure on kidney section and resulted in no staining in tissue.

\subsection{Data Acquisition and Analysis}

Microscopy and capturing was made by using BX61 epiflourescent microscope (Olympus, Tokyo, Japan) equipped with cooled digital camera (DP71, Olympus, Tokyo, Japan). Areas of the cortex containing proximal tubuli were captured under a 40x objective magnification. Microphotographs were analyzed by using Image $\mathbf{J}$ softvare (National Institutes of Health, Bethesda, MD, SAD). We analyzed calibrated and tresholded 8-bit photographs (Fig. 2). Analysis was made in $2000 \mu \mathrm{m}^{2}$ squares covered at least $80 \%$ with proximal tubuli. The mean percentage area for animal was calculated.

\subsection{Statistical Analysis}

Softvare program GraphPad Prism 5 (McIntosh, CA, SAD) was used for the statistical analysis. Kruskal-Wallis test, and Dunn post hoc test were used to compare differences between groups. $\mathrm{p}<0.05$ was considered statistically significant.

\section{Results}

Obtained results have shown that Suc group had significantly increased blood glucose in comparison to $\mathrm{C}$ group 20 weeks after the beginning of the study $(\mathrm{p}<0,05)$. However, concentration of the blood glucose in Suc/TA group did not significantly differ in comparison to both, C or Suc group (Fig. 1).

Histological sections of the kidneys of the experimental animals stained by Mallory revealed advanced damage in groups Suc and Suc/TA. In group Suc, large number of damaged proximal tubuli is apparent, along with the damage of the glomeruli. In the kidneys of the Suc/TA rats, damage was more pronounced, with visible signs of the sclerosis (Fig. 2).

On histological sections of the kidneys of the experimental rats, strong immunoreactivity of the connexin 45 could be observed in PTCs. Connexin 45 immunoreactivity was not found in glomeruli and cells of the distal tubuli (Fig. 3). Connexin 45 expression was the highest in the control group.

It decreased in Suc group (but not statistically) and the lowest was in Suc/TA group. Analysis of the microphotographs revealed significantly smaller percentage area covered with $\mathrm{Cx} 45$ immunofluorescence in Suc/TA, in comparison to $\mathrm{C}$ group ( $\mathrm{p}<0.05$; Fig. 4 ).

\section{DISCUSSION}

An influence of tannic acid on expression of the Cx45 in rat kidney damaged by chronic high sucrose treatment was studied. Increased blood glucose of the rats in Suc group confirm the model of DM2 (Fig. 1). Pathohistology of the kidney sections showed that long-term high sucrose ingestion caused damage of the PTCs and glomeruli (Fig. 2). Addition of the tannic acid resulted in more pronounced damage, with apparent sclerosis of glomeruli and tubuli (Fig. 2).

Connexins are trans-membrane proteins that form gap junctions and hemichannels important for ion and small molecule exchange between cells (Meda, 1996, Lawrence et al., 1978, Saez et al., 1989). They are important for the normal function of many organs. It was already known that DM changes the regulation and expression of the connexins (Hanner et al., 2010). Taking into consideration different (often opposite) effects of the tannic acid in different pathological conditions, we aimed to see whether tannic acid causes changes of connexin expression in rat kidney, in condition of high glucose load. Certain homology between connexins in human, mouse and rat was found previously; hence mouse and rat could be used as good experimental models for human disorders.

In opposite to previous research, we found strong $\mathrm{Cx} 45$ immunoreactivity exclusively in PTCs. This is not in agreement with studies that found the presence of $\mathrm{Cx} 45$ in renal arterioles 
and in glomerular cells (Kurtz et al., 2009) (Butterweck et al., 1994). We did not find Cx45 imunoreactivity in glomerular cells, distal tubular cells nor in the blood vessels of the kidney. Mentioned differences could be attributed to different antibody specificity. Potential differences between species and strains should be also taken into consideration.

However, we observed the decrease in the $\mathrm{Cx} 45$ expression in PTCs, which was statistically significant in group of rats that received tannic acid along with the sucrose treatment. In agreement to our results, many researches pointed to the decrease of the expression of the different connexin isoforms in different tissues during $\mathrm{DM}$. $\mathrm{Li}$ and collaborators found that DM2 resulted in a decrease of Cx40 expression in myocardium of the left atrium, with consequent prolongation of the $\mathrm{P}$-wave, while expression of $\mathrm{Cx} 43$ stayed unchanged ( $\mathrm{Li}$ et al., 2016). It was also found that decreased expression of Cx36 in beta cells of the diabetic mice contributes the pathophysiology of the DM2 (Short et al., 2014). Yu and collaborators observed increased $\mathrm{Cx} 43$ expression in a cell culture of the epithelial lung cells after exposure to the high glucose medium ( $\mathrm{Yu}$ et al.). The decreased retinal expression of $\mathrm{Cx} 43$ and Cx30.2, particularly in retinal blood vessels, has been related to the development of the diabetic retinopathy (Tien et al., 2016, Durham et al., 2015, Tien et al., 2014) (Manasson et al., 2013). Concerning renal pathology, it was found that 43 expression decreased in PTCs of the Sprague-Dalwey rats due to DM2 (Satriano et al., 2010).
The above mentioned studies are in agreement with our results that indicate the decrease in 45 expression in kidney that were damaged by chronic high sucrose intake, particularly in animals treated with tannic acid. This decrease of the $\mathrm{Cx} 45$ expression could be explained by strong damage of the PTCs caused by renal glucose overload, that could damage the kidney directly, as well as indirectly, trough the hemodynamic modifications (Schena and Gesualdo, 2005, Kanwar et al., 2008). Connexins are continuously exposed to fluctuations in charge, phosphorylation and oxidative stress and they have very short halflife and large turnover (Alexander and Goldberg, 2003, Saffitz et al., 2000, Hanner et al., 2010). Hence, it could be expected that the damage of the PTCs, caused by glucose overload, will cause disturbance in $\mathrm{Cx} 45$ cell trafficking having as a consequence the decrease in $\mathrm{Cx} 45$ expression. The role of the connexins in PTCs has not been completely enlightened. We could only assume that the absence of the intercellular communication due to disturbed connexin trafficking could cause additional damage in the PTCs function and contribute to the development of the diabetic complications.

Although we previously believed that that the renal damage in DM starts in glomerulus, recently we became aware that the PCT are initially damaged, and that their dysfunction is leading to the glomerular filtration membrane damage (Gilbert, 2017). Hence, the dynamics of the connexin expression in PTCs during different DM treatments could be of the extreme importance for the pathophysiology and treatment of the diabetic renal complications.

Figures and Figure Captions

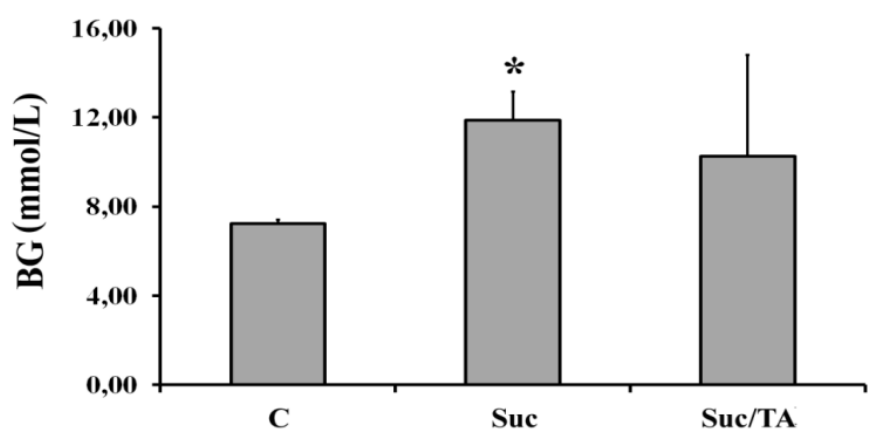

Figure1. Blood glucose of rats in all experimental and control groups after 20 weeks of treatment $B G$-blood glucose; C - control group; Suc - group of rats that was consuming 30\% sucrose; Suc/TA - group of rats that was consuming $30 \%$ sucrose with $0.1 \%$ of tannic acid. Data are shown as mean \pm standard deviation. * statistically significant difference in comparison to the control group $p<0.05$. 


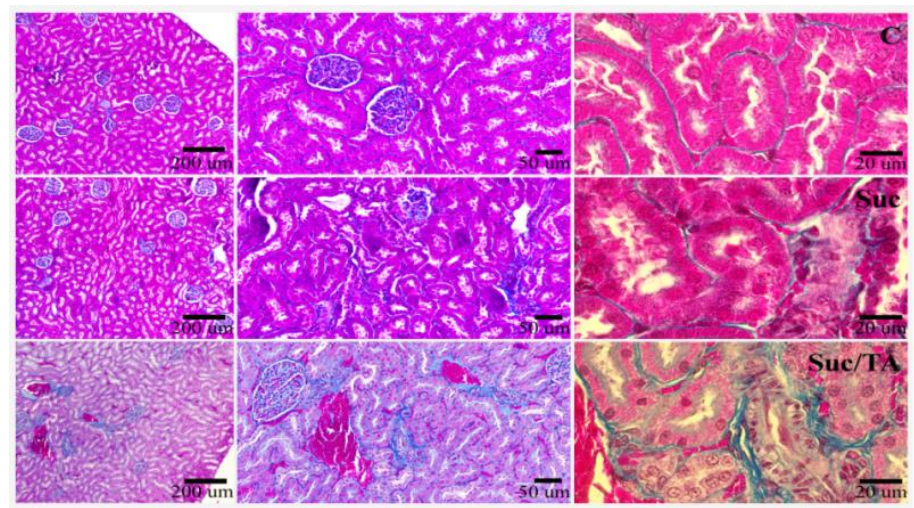

Figure2. Representative figures of the morphological changes in kidneys caused by chronic sucrose treatment and tannic acid. Histological sections of kidneys stained by trichrome Mallory staining. Objective magnification 4x; 10x and 40x. C - control group; Suc - group of rats that was consuming 30\% sucrose; Suc/TA - group of rats that was consuming $30 \%$ sucrose with $0.1 \%$ of tannic acid. Data are shown as mean \pm standard deviation.

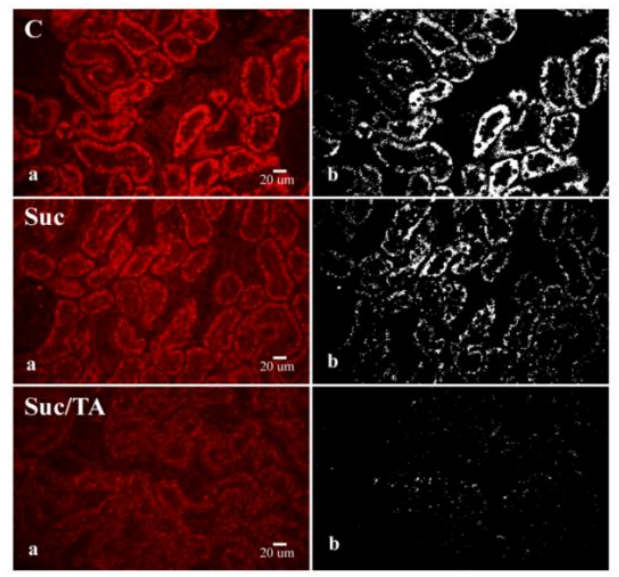

Figure3. Representative figures of the connexin 45 (Cx45) expression during chronic sucrose treatment and tannic acid tretment. Histological sections of kidneys stained by immunofluorescence (a). Objective magnification 40x. C-control group; Suc - group of rats that was consuming 30\% sucrose; Suc/TA - group of rats that was consuming $30 \%$ sucrose with $0.1 \%$ of tannic acid. The same microphotographs tresholded for the analysis by using ImageJ programme (b).

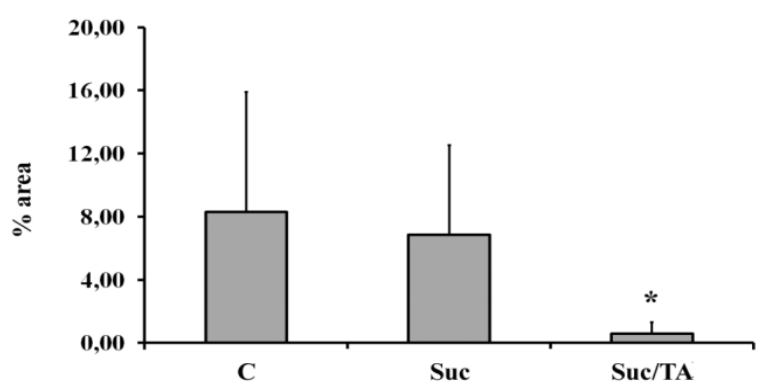

Figure4. Graphical display of the changes in the connexin 45 (Cx45) expression caused by chronic sucrose treatment and tannic acid. C - control group; Suc - group of rats that was consuming 30\% sucrose; Suc/TA group of rats that was consuming $30 \%$ sucrose with $0.1 \%$ of tannic acid. Results are expressed as percentage of the analyzed tubular area under the imunofluorescence, Data are shown as mean \pm standard deviation. * statistically significant difference in comparison to the control group $p<0.05$.

\section{ACKNOWLEDGMENTS}

This work has been supported in part by Croatian Science Foundation under the project
(IP-2014-09-8992; T. Mašek) and by Ministry of Science, Education and Sports of the Republic of Croatia support (N. Filipović). 
The Influence of the Tannic Acid on the Expression of the Connexins 45 in a Rat Kidney Damaged by the Chronic Hyperglycemia

\section{REFERENCES}

[1] AGNIC, I., VUKOJEVIC, K., SARAGABABIC, M., FILIPOVIC, N. \& GRKOVIC, I. (2014) Isoflurane post-conditioning stimulates the proliferative phase of myocardial recovery in an ischemia-reperfusion model of heart injury in rats. Histol Histopathol, 29, 89-99.

[2] AKIYAMA, H., FUJII, K., YAMASAKI, O., OONO, Y. \& IWATSUKI, K. (2001) Antibacterial action of several tannins against Staphylococcus aureus. Journal of Antimicrobial Chemotherapy, 48, 487-91.

[3] ALEXANDER, D. B. \& GOLDBERG, G. S. (2003) Transfer of biologically important molecules between cells through gap junction channels. Curr Med Chem, 10, 2045-58.

[4] ARENSBAK, B., MIKKELSEN, H. B., GUSTAFSSON, F., CHRISTENSEN, T. \& HOLSTEIN-RATHLOU, N. H. (2001) Expression of connexin 37, 40, and 43 mRNA and protein in renal preglomerular arterioles. Histochem Cell Biol, 115, 479-87.

[5] BUTTERWECK, A., GERGS, U., ELFGANG, C., WILLECKE, K. \& TRAUB, O. (1994) Immunochemical characterization of the gap junction protein connexin45 in mouse kidney and transfected human HeLa cells. J Membr Biol, 141, 247-56.

[6] CAO, G., SOFIC, E. \& PRIOR, R. L. (1997) Antioxidant and prooxidant behavior of flavonoids: structure-activity relationships. Free Radic Biol Med, 22, 749-60.

[7] CHU, X., WANG, H., JIANG, Y., ZHANG, Y., BAO, Y., ZHANG, X., ZHANG, Y., GUO, H., YANG, F., LUAN, Y. \& DONG, Y. (2016) Ameliorative effects of tannic acid on carbon tetrachloride-induced liver fibrosis in vivo and in vitro. Journal of Pharmacological Sciences, 130, 15-23.

[8] CHUNG, K. T., WONG, T. Y., WEI, C. I., HUANG, Y. W. \& LIN, Y. (1998) Tannins and human health: a review. Crit Rev Food Sci Nutr, 38, 421-64.

[9] DE BOER, I. H., RUE, T. C., HALL, Y. N., HEAGERTY, P. J., WEISS, N. S. \& HIMMELFARB, J. (2011) Temporal trends in the prevalence of diabetic kidney disease in the United States. JAMA, 305, 2532-9.

[10] DURHAM, J. T., DULMOVITS, B. M., CRONK, S. M., SHEETS, A. R. \& HERMAN, I. M. (2015) Pericyte chemomechanics and the angiogenic switch: insights into the pathogenesis of proliferative diabetic retinopathy? Invest Ophthalmol Vis Sci, 56, 3441-59.

[11] FILIPOVIC, N., ZUVAN, L., MASEK, T., TOKALIC, R. \& GRKOVIC, I. (2014) Gender and gonadectomy influence on neurons in superior cervical ganglia of sexually mature rats. Neurosci Lett, 563, 55-60.
[12] GILBERT, R. E. (2017) Proximal Tubulopathy: Prime Mover and Key Therapeutic Target in Diabetic Kidney Disease. Diabetes, 66, 791-800.

[13] GIN, H., RIGAlleAU, V., CAUBET, O., MASQUELIER, J. \& AUBERTIN, J. (1999) Effects of red wine, tannic acid, or ethanol on glucose tolerance in non-insulin-dependent diabetic patients and on starch digestibility in vitro. Metabolism, 48, 1179-83.

[14] GUPTA, S., SAHA, B. \& GIRI, A. K. (2002) Comparative antimutagenic and anticlastogenic effects of green tea and black tea: a review. Mutat Res, 512, 37-65.

[15] HAMELIN, R., ALLAGNAT, F., HAEFLIGER, J. A. \& MEDA, P. (2009) Connexins, diabetes and the metabolic syndrome. Curr Protein Pept Sci, 10, 18-29.

[16] HANNER, F., SORENSEN, C. M., HOLSTEIN-RATHLOU, N. H. \& PETIPETERDI, J. (2010) Connexins and the kidney. Am J Physiol Regul Integr Comp Physiol, 298, R1143-55.

[17] KANWAR, Y. S., WADA, J., SUN, L., XIE, P., WALLNER, E. I., CHEN, S., CHUGH, S. \& DANESH, F. R. (2008) Diabetic nephropathy: mechanisms of renal disease progression. Exp Biol Med (Maywood), 233, 411.

[18] KURTZ, L., JANSSEN-BIENHOLD, U., KURTZ, A. \& WAGNER, C. (2009) Connexin expression in renin-producing cells. J Am Soc Nephrol, 20, 506-12.

[19] LABIENIEC, M. \& GABRYELAK, T. (2003) Effects of tannins on Chinese hamster cell line B14. Mutat Res, 539, 127-35.

[20] LAWRENCE, T. S., BEERS, W. H. \& GILULA, N. B. (1978) Transmission of hormonal stimulation by cell-to-cell communication. Nature, 272, 501-6.

[21] LI, B., PAN, Y. \& LI, X. (2016) Type 2 Diabetes Induces Prolonged P-wave Duration without Left Atrial Enlargement. J Korean Med Sci, 31, 525-34.

[22] MANASSON, J., TIEN, T., MOORE, C., KUMAR, N. M. \& ROY, S. (2013) High glucose-induced downregulation of connexin 30.2 promotes retinal vascular lesions: implications for diabetic retinopathy. Invest Ophthalmol Vis Sci, 54, 2361-6.

[23] MASEK, T. \& STARCEVIC, K. (2016) Lipogenesis and lipid peroxidation in rat testes after long-term treatment with sucrose and tannic acid in drinking water. Andrologia.

[24] MEDA, P. (1996) [Role of intercellular communication via gap junctions in insulin secretion]. Ann Endocrinol (Paris), 57, 481-3.

[25] MICHISHITA, R., MATSUDA, T., KAWAKAMI, S., TANAKA, S., KIYONAGA, A., TANAKA, H., MORITO, N. 
The Influence of the Tannic Acid on the Expression of the Connexins 45 in a Rat Kidney Damaged by the Chronic Hyperglycemia

\& HIGAKI, Y. (2017) Hypertension and hyperglycemia and the combination thereof enhances the incidence of chronic kidney disease (CKD) in middle-aged and older males. Clin Exp Hypertens, 39, 645-654.

[26] RAI, P., SINGH, T., LEDERMAN, R., CHAWLA, A., KUMAR, D., CHENG, K., VALECHA, G., MATHIESON, P. W., SALEEM, M. A., MALHOTRA, A. \& SINGHAL, P. C. (2015) Hyperglycemia enhances kidney cell injury in HIVAN through down-regulation of vitamin D receptors. Cell Signal, 27, 460-9.

[27] SAEZ, J. C., CONNOR, J. A., SPRAY, D. C. \& BENNETT, M. V. (1989) Hepatocyte gap junctions are permeable to the second messenger, inositol 1,4,5-trisphosphate, and to calcium ions. Proc Natl Acad Sci U S A, 86, 2708-12.

[28] SAFFITZ, J. E., LAING, J. G. \& YAMADA, K. A. (2000) Connexin expression and turnover : implications for cardiac excitability. Circ Res, 86, 723-8.

[29] SAMPANIS, C. (2008) Management of hyperglycemia in patients with diabetes mellitus and chronic renal failure. Hippokratia, 12, 22-7.

[30] SATRIANO, J., MANSOURY, H., DENG, A., SHARMA, K., VALLON, V., BLANTZ, R. C. \& THOMSON, S. C. (2010) Transition of kidney tubule cells to a senescent phenotype in early experimental diabetes. Am J Physiol Cell Physiol, 299, C374-80.

[31] SCHENA, F. P. \& GESUALDO, L. (2005) Pathogenetic mechanisms of diabetic nephropathy. J Am Soc Nephrol, 16 Suppl 1, S30-3.

[32] SHORT, K. W., HEAD, W. S. \& PISTON, D. W. (2014) Connexin 36 mediates blood cell flow in mouse pancreatic islets. Am J Physiol Endocrinol Metab, 306, E324-31.

[33] SILVERSTEIN, D. M., THORNHILL, B. A., LEUNG, J. C., VEHASKARI, V. M., CRAVER, R. D., TRACHTMAN, H. A. \& CHEVALIER, R. L. (2003) Expression of connexins in the normal and obstructed developing kidney. Pediatr Nephrol, 18, 21624.
[34] TEIXEIRA, S., SIQUET, C., ALVES, C., BOAL, I., MARQUES, M. P., BORGES, F., LIMA, J. L. \& REIS, S. (2005) Structureproperty studies on the antioxidant activity of flavonoids present in diet. Free Radic Biol Med, 39, 1099-108.

[35] TIEN, T., MUTO, T., BARRETTE, K., CHALLYANDRA, L. \& ROY, S. (2014) Downregulation of Connexin 43 promotes vascular cell loss and excess permeability associated with the development of vascular lesions in the diabetic retina. Mol Vis, 20, 73241.

[36] TIEN, T., ZHANG, J., MUTO, T., KIM, D., SARTHY, V. P. \& ROY, S. (2016) High Glucose Induces Mitochondrial Dysfunction in Retinal Muller Cells: Implications for Diabetic Retinopathy. Invest Ophthalmol Vis Sci, 58, 2915-2921.

[37] TIKOO, K., TAMTA, A., ALI, I. Y., GUPTA, J. \& GAIKWAD, A. B. (2008) Tannic acid prevents azidothymidine (AZT) induced hepatotoxicity and genotoxicity along with change in expression of PARG and histone H3 acetylation. Toxicol Lett, 177, 90-6.

[38] TRIPLITT, C. L. (2012) Understanding the kidneys' role in blood glucose regulation. Am J Manag Care, 18, S11-6.

[39] YOKOZAWA, T., OURA, H., HATTORI, M., IWANO, M., DOHI, K., SAKANAKA, S. \& KIM, M. (1993) Inhibitory effect of tannin in green tea on the proliferation of mesangial cells. Nephron, 65, 596-600.

[40] YU, H., YANG, J., ZHOU, X., XIAO, Q., LU, Y. \& XIA, L. High glucose induces dysfunction of airway epithelial barrier through downregulation of connexin 43. Exp Cell Res, 342, 11-9.

[41] ZHAO, T., SUN, Q., DEL RINCON, S. V., LOVATO, A., MARQUES, M. \& WITCHER, M. (2014) Gallotannin imposes S phase arrest in breast cancer cells and suppresses the growth of triple-negative tumors in vivo. PLoS One, 9, e92853.

[42] ZHOU, M., LI, Z., MIN, R., DONG, Y., SUN, Q. \& LI, Y. (2015) Log (TG)/HDL-C ratio as a predictor of decreased islet beta cell function in patients with type 2 diabetes: 6-year cohort study. J Diabetes, 7, 689-98

Citation: Mia Šarić, Tomislav Mašek, Natalija Filipović. The Influence of the Tannic Acid on the Expression of the Connexins 45 in a Rat Kidney Damaged by the Chronic Hyperglycemi. ARC Journal of Diabetes and Endocrinology.2017; 3(2):11-17. doi:dx.doi.org/10.20431/2455-5983.0302002.

Copyright: (C) 2017 Authors. This is an open-access article distributed under the terms of the Creative Commons Attribution License, which permits unrestricted use, distribution, and reproduction in any medium, provided the original author and source are credited. 